\title{
Espejos, reflejos e imaginarios: el diario Mundo al Día (1924-1938) ${ }^{1}$
}

\author{
Susana Friedmann² \\ King's College
}

\begin{abstract}
Resumen: Mediante un análisis del texto y de la imagen del diario gráfico colombiano Mundo al día, publicado entre 1924 y 1938 (cuya presencia no ha sido legitimizada por nuestros historiadores y periodistas en comparación con otros periódicos más reconocidos), este artículo muestra cómo paulatinamente en los años veinte surge una nueva forma de periodismo. Lo que anteriormente constituía un periodismo de elite social e intelectual que circulaba entre un grupo reducido de gente letrada con un cierto nivel de cultura y una enorme avidez por la noticia se convierte aquí en un periodismo con un enfoque bastante diferente que no se puede desvincular del advenimiento de la modernidad y de la industrialización en Colombia ni de las nuevas tecnologías de la información. La comunicación visual forma parte significativa en una serie de estrategias para lograr un cubrimiento masivo de lo noticioso.
\end{abstract}

Palabras Claves: Comunicación visual; Colombia; Modernidad; Memoria; Identidad Cultural

\begin{abstract}
By means of an analysis of the daily newspaper Mundo al día published between 1924 and 1938, whose presence has not been legitimized by our historians and journalists (compared to other newspapers that are more wellknown), this article shows how gradually in the twenties a new kind of journalism emerges. What previously was a journalism for a social and intellectual elite that circulated among a reduced number of literate people with a certain cultural level as well as an enormous avidness for the latest news transforms itself into a journalism that has a different focus that cannot be separated from the rise of modernity and industrialization in Colombia nor from the new technologies in the age of information. Visual communication constitutes a significant part of a series of strategies that aim at a massive coverage of the news.
\end{abstract}

Key words: Visual communication; Journalism; Modernity; Memory; Cultural Identity.

\footnotetext{
${ }^{1}$ Nombre de la exposición que se presentó en noviembre del año 2004 en la Biblioteca Virgilo Barco como parte del proyecto "Re-Construyendo lo propio" financiado por una beca Prometeo 2003 y la Dirección Académica de la Universidad Nacional de Colombia.

${ }_{2}$ Profesora emérita de la Universidad Nacional de Colombia. Musicóloga con doctorado de King's College, Londres, adscrita al Instituto de Investigaciones Estéticas de la Facultad de Artes. Autora de varios libros y numerosos artículos sobre la identidad musical colombiana y la transmisión cultural. Actualmente coordina la Maestría de Estudios Culturales de la misma institución.
} 
Las secuelas de la vertiginosa automatización, de la producción en serie y lo que Walter Benjamin llamaría "la era de la reproductibilidad técnica" trastocan la esencia misma de la percepción del mundo en todas sus proyecciones. Reflejo de ello en el campo del periodismo, es lo que pretende abordarse en este escrito sobre la evolución de la mirada de primer diario gráfico colombiano intitulado Mundo al dia y cuya difusión cubre el período de 1924 a 1938.3

Según Traversa,

La figura que se estampa en la tela, en el metal del daguerrotipo o en el papel fotográfico no es una figura distante en vertical tal cual la del cuerpo del soberano- que comporta por su sola presencia una jerarquía-; su distancia ahora será horizontal, reproduce la topografía de la ciudad, enrasadora engañosa de las viejas jerarquías. Sus especies icónicas dominantes serán el retrato y la escena de costumbres, de las que la caricatura de prensa fue un preanuncio. ${ }^{4}$

El extremo abismal entre la construcción del objeto elaborado manualmente o de la obra de arte con su halo de lo sacro, como objeto único e inigualable, llevado a una producción industrial que se concreta mediante su multiplicación instantánea, amplía el campo de lo visible y de lo exponible, del tiempo y del espacio, abarcando lo común y lo cotidiano, pero también lo que, sin haber existido antes, ahora se convertiría en una necesidad en ese tránsito de la vida rural a la urbana, de la privada a la pública se expone sin pudor. Todo aquello coincide con transformaciones de carácter tecnológico de suma importancia, aún para el periodismo del mundo entero. ${ }^{5}$

En pocos años se revolucionó el campo de la fotografía y el de la litografía, pero también a nivel económico, la producción de papel se redujo a unos costos irrisorios y a unas velocidades jamás sospechadas anteriormente. Por nombrar tan

\footnotetext{
${ }^{3}$ Según Alcides Arguedas en su libro La danza de las sombras (1934), el tiraje de los principales diarios del país en 1930 era el siguiente: El Tiempo: 30.000 ejemplares diarios y 50.00o los domingos, Mundo al día: 20.000 ejemplares diarios y 40.000 los sábados, $E l$ Espectador: 15.000 diarios. Citado en Holguín Holguín, Andrés, "Literatura y Pensamiento 1886-1930" en Nueva Historia de Colombia, dir. Alvaro Tirado Mejía. Bogotá, Planeta Editorial, 1989, T. VI, 54.

${ }^{4}$ Traversa, Oscar. Cuerpos de papel. Figuraciones del cuerpo en la prensa 1918-1940. Barcelona: Editorial Gedisa, 1997, 21.

${ }^{5}$ Ibid., 21.
} 
sólo un aspecto, las industrias comienzan a gastar más en publicidad que en otros aspectos transcendentales para determinado negocio. ${ }^{6}$ Por supuesto esto se traduce en consecuencias significativas para la evolución de este medio de comunicación y ante todo contribuye directamente al espectacular ascenso en el número de lectores y en la difusión de las noticias. En el caso colombiano, específicamente en el diario gráfico Mundo al día (1924-1938), la transmisión de la noticia por cable implicó la adhesión a poderosas redes internacionales de información, un aspecto que indudablemente afectó la mirada de un público cada vez más amplio, por un lado abriéndola a un mundo más extendido y complejo, pero también a otras estructuras mentales y a diferentes formas y expectativas en lo que se refiere a la de calidad de vida.

Quizás el intelectual que mejor expresó esta coyuntura de lo mecánico y la automatización es Paul Valéry, con su lúcido y frecuentemente citado comentario sobre las múltiples implicaciones del advenimiento de la modernidad a punta de oprimir un botón. ${ }^{7}$

Comme l'eau, comme le gaz, comme le courant électrique viennent de loin, dans nos demeures, répondre à nos besoins moyennant un effort quasi nul, ainsi serons-nous alimentés d'images visuelles et auditives, naissant et s'évanouissant au moindre geste, presqu'à un signe.

Como el agua, como el gas, como la corrriente eléctrica vienen de lejos, en nuestros hogares, responder a nuestras necesidades requiriendo un esfuerzo pácticamente nulo, nos predispone a alimentarnos de imágenes visuales y auditivas que nacen y desaparecen con el más mínimo gesto, casi con una señal mínima.

En lo que se refiere al Mundo al día, este periódico presentó el más grande acopio de material gráfico de su época, con temas centrados obsesivamente en el progreso del país, ante todo en los adelantos tecnológicos en materia de transporte, de comunicaciones (cable, teléfono, radio y cine), del equipamiento urbano de las ciudades (servicios de electrificación, de acueducto y de higiene) y de la socialización de sus integrantes (diversas celebraciones de carácter nacional, histórico, religioso y rituales profanos como los deportes y el mundo del entretenimiento-- entre todos

\footnotetext{
${ }^{6}$ Goodrum, Charles y Helen Dalrymple. Advertising in America. The First 200 Years. Nueva York, Harry N. Abrams Inc., Publishers, 1990, 216.

${ }^{7}$ Citado en Traversa, op. cit., p. 32. La traduccción es mía.
} 
éstos, actividades no sólo públicas sino también rescatando actividades privadas de interés limitado a ciertos grupos sociales), sin pasar de alto el incrementado posicionamiento de la mujer como lectora de peso que requiere estar al día con la moda internacional, con su hogar dotado al tono con la época.

Se destaca en este periódico, además del seguimiento bastante prudente de la actualidad nacional, algunos íconos significativos que marcan hitos de la actualidad nacional, curiosamente centrádose en el campo artístico, tal como la difusión de la música nacional, el advenimiento de la cinematografía nacional y la serie de tribulaciones que sufrió la emisión radial colombiana, además de tocar temas más convencionales que claramente se asimilan a modelos exógenos como lo son la ópera, el teatro, la zarzuela y las películas extranjeras. Ya se ha comentado en otras ocasiones la insólita idea de publicar semanalmente una partitura de música nacional como una manera de inculcar la conciencia de una manera de representar una nación con identidad propia y singular. ${ }^{8}$

La función del periódico Mundo al dia entonces fue la de representar la sociedad colombiana como ésta se quiere ver, mostrando en primer lugar lo que considera que es y debe ser el país visto desde adentro, pero también proyectándolo hacia el mundo exterior, más allá de las topográficamente accidentadas e intransitables fronteras nacionales.

Significativamente, esto está relacionado también con el tema de la seducción, del consumo y de la publicidad en Mundo al día. Esto se manifiesta de manera inequívoca en el esmero y la calidad extraordinaria del diseño, aspecto raras veces observado en periódico alguno y mucho menos en nuestro país en esta época. En material de ilustración, de fotografía, de grabado, ante todo en las ilustraciones de las secciones de cuentos, y de poesía, en los cabezotes, en las caricaturas, en los diseños de moda y en la primera tira cómica del país, se invita al lector a consumir un producto de gusto impecable y de indiscutible distinción. Asimismo, los avisos de publicidad ocupan un papel aún más poderoso, no sólo a nivel de impacto visual sino también por las cuantiosas implicaciones de carácter económico para el periódico.

\footnotetext{
${ }^{8}$ Revivamos nuestra música. Ed. Susana Friedmann. Compact disk publicado por la División de Investigación de la Universidad Nacional de Colombia con auspicio de la convocatoria Becas Prometeo 2001. Bogotá: Talea Estudio con Editorial Unibiblos, 2002, 1.
} 
Por decir algo, así como en las series publicitarias de artículos de primera necesidad, tratados con extensos textos, algunos de carácter educativo, otros de carácter lúdico y seductor, y en las caricaturas sobre aquellos artículos que no se requerían ni siquiera se conocían antes pero que ahora los productores quieren convertir en artículos de primera necesidad, se logra persuadir al público en general que no puede existir sin artículos que de un momento a otro forman parte integral de toda una indumentaria que es signo de actualización y distinción en ese mundo que se perfila y se proyecta en la nutrida sección de avisos comerciales del periódico, cuyo interés no ha pasado inadvertido.

La ingerencia de proporciones, porqué no decirlo, globales, de la industria, sea la automotriz, la disquera, la de los electrodomésticos y, aunque hasta ahora se menciona, el énfasis desde el comienzo en el campo de la salud, de la higiéne y de la belleza, son aspectos que debe asumir todo individuo moderno, culto y letrado, que tiene trazado el camino para conservar su profesión, su familia y es más, para apropriarse de una identidad construida con todos los pormenores del cuerpo físico ideal. Todo esto, claramente posicionado estratégicamente desde el primer día que circula el periódico, en que se vislumbra en cada una de sus páginas el interés en un tema de fuertes implicaciones económicas.

Con la excepción de una serie de fotos impactantes sobre la huelga bananera de la United Fruit de 1929, acompañada de escritos breves y escuetos, dos artículos sobre el caso de Quintin Lame, una serie de escritos de José Eustacio Rivera sobre la situación crítica de los caucheros del Caquetá y una que otra noticia sobre los primeros indicios de lo que se va a desembocar en la guerra con el Perú, se destacan de vez en cuando algunos artículos escasos pero nutridos sobre la mendicidad y las condiciones de hacinamiento del proyecto urbano así como un considerable número de carátulas y caricaturas que ponen de presente las perpetuas paradojas de nuestra idiosincracia nacional.

\section{Hacia una nueva tipología}

Habiendo presentado un breve panorama de este periódico, cuya presencia no ha sido legitimizada (en comparación con el periódico El Tiempo, El Espectador o la revista Cromos y El Gráfico, más reconocidas por nuestros historiadores y 
periodistas), lo que se pretende aquí es mostrar cómo paulatinamente en los años veinte surge una nueva forma de periodismo. Lo que anteriormente constituía un periodismo de elite social e intelectual que circulaba entre un grupo reducido de gente letrada con un cierto nivel de cultura y una enorme avidez por la noticia se convierte aquí en un periodismo con un enfoque bastante diferente que no se puede desvincular del advenimiento de la modernidad y de la industrialización en Colombia.

En el caso del Mundo al día se trata de un periodismo que se canaliza a través de y para lo comercial, y que por lo tanto, aunque representa un paso firme hacia la difusión masiva-- no tanto de la noticia-también se construye a partir de los intereses, en este caso, de una élite commercial, ${ }^{9}$ consciente del enorme potencial de las nuevas industrias culturales y deseosa de dirigir sus estrategias de mercadeo y de publicidad hacia una inmensa minoría, gran parte de la cual ni siquiera puede leer ${ }^{10}$

\footnotetext{
${ }^{9}$ El propietario de Mundo al día, Arturo Manrique, nieto del prócer de la Independencia, Juan Nepomuceno Contreras +1780 ), se destacó como comerciante y periodista, y ha sido reconocido por haber introducido grandes adelantos en la tecnología de composición e impresión al país. Desde 1902, cuando publicó el periódico literario La Esfinge, que dio impulso a una nueva generación de críticos, escritos, poetas y periodistas, dividió su atención a sus actividades como director con las de puente para establecer contacto con importantes empresas que lideraban la producción de los principales periódicos a nivel mundial. En 1904 se trasladó a Barranquilla para fundar y dirigir el diario Rigoletto, vinculando de ahí en adelante a varios destacados escritores y periodistas a sus actividades periodísticas y en 1910 trajo para la Gaceta Republicana el primer linotipo que se conoció en Colombia. Montó la primera máquina rotativa tipo duplex para El Diario Nacional de Enrique Olaya Herrera, seguiendo con su vinculación a importantes periódicos como el Correo Nacional, La Tribuna y La Prensa, además de tener una significativa carrera en el campo del periodismo, así como en empresas como su Papelería Manrique y la Editorial del mismo nombre. En 1918 fue nombrado primer Vicepresidente de la Cámara de Comercio de Bogotá, reconocido en ese entonces por sus actividades comerciales en la importación y comercialización de vehículos que lo llevó a fundar la empresa Transportes Brockway, una flotilla de camiones con recorridos hasta Boyacá y que prestaban servicio de contratistas con el Correo del Norte (Rondón, César. Inédito, 2005, 14). Accionista y miembro de la Junta Directiva con Eduardo Santos, director del diario El Tiempo y Abraham Cortés, codirector de la revista El Gráfico de la Compañía Radiotelefónica de Colombia (MD 7 de febrero, 1925, 8) y en 1932, inauguró la radiodifusora de Mundo al día (MD 25 de noviembre, 1932, 17). Los nexos con el proyecto de desarrollo de las comunicaciones y del transporte como objetivo del Estado indudablemente estuvo en manos de comerciantes como Manrique, cuya ingerencia en la representación de empresas como la General Electric, que distribuía no sólo electrodomésticos al país, sino también tenía vínculos con la industra de tranportes terrestres y aéreos también tuvo mucho que ver con el desarrollo de la industria cinematográfica del país y la difusión de la música colombiana en estaciones radiales del exterior.

${ }^{10}$ Según Marco Palacio y Frank Safford, para el año 1920, el 66\% de la población mayor de 15 años era analfabeta, proporción qie disminuyó al 48\% en 1950. Ver Colombia. País
} 
pero que asimila todo aquello que puede acceder visualmente, o sea, mediante la ilustración, la fotografía, la tira cómica o la caricatura y el aviso publicitario.

Con la consolidación del periódico como un importante agente de identidad y de posicionamiento a nivel nacional e internacional, Mundo al día se transforma en un agente de construcción de una memoria que incialmente apunta hacia lo singular y lo propio pero con el tiempo se reduce al uso y al consumo de la mercancía más que de la noticia.

En las páginas que siguen, se mostrará primero cómo cambia la construcción de lo noticioso a través de los titulares del periódico que reflejan un tratamiento que se desdibuja notablemente, llegando a un cubrimiento superficial y poco crítico de sucesos de transcendencia a nivel mundial. Para ello se procedió con el análisis de los indices del periódico ${ }^{11}$, seleccionando un cierto evento considerado como el más representativo de cada año desde el inicio del periódico hasta su clausura $^{12}$ y se sometió al escrutinio de los titulares para confirmar si en efecto el acontecimiento se registró o no, siguiendo el modelo del gatekeeping propuesta inicialmente por David White y elaborada por Stella Martini en su Periodismo, noticia y noticiabilidad (2000). ${ }^{13}$

El ejercicio comparativo se logró mediante una primera confrontación sobre la noticia internacional y luego mismo sobre la noticia a nivel nacional. Para señalar el valor y el significado de lo visual, se extendió el análisis al uso y consumo de las imagenes en las carátulas, los grabados y las fotografías del periódico. El objetivo en parte, era de indagar si existe una relación entre lo escrito y las imagines o si no hay conexión entre ellas. También era importante averiguar si existía una jerarquización entre estos dos tipos de información, aspecto sobre el cual se pudo señalar cómo en ocasiones falta una articulación clara entre comunicación textual y comunicación visual y todo el contrario, se subvierte la jerarquía de lo escrito por lo visual. Finalmente, se procedió con el análisis de la publicidad, sus fuentes y su manejo, con

\footnotetext{
fragmentado, Sociedad dividida. Su Historia. Bogotá, Grupo Editorial Norma, 2002, 504. La prensa sensacionalista y los sectores populares. Barcelona, Editorial Norma, 2001, 14.

${ }^{11}$ Pineda, Juan Gabriel. Documento inédito, 2004. Asistente de investigación de la Beca Prometeo 2003.

${ }^{12}$ www.historyexplorer.net

${ }^{13}$ Martini, 74.
} 
el fin de mostrar cómo el periódico se convirtió-- en vez de una herramienta forjadora de cultura y portadora de información-- en su propia agencia, no solo de noticias, sino también de publicidad, de radio, y así en una herramienta de seducción y de encanto parecido al que se acostumbra asociar con una mercancía. En este proceso, paradójicamente, persistió un atractivo singular: el de incluir una tira cómica semanal así como una colección de partituras musicales que de una manera u otra se articulaban con los acontecimientos tratados en el periódico, ambos de las cuales se sometieron a un análisis de contenido y de recepción.

Adicionalmente, se señala en este artículo cómo el uso y el consumo de la radio, ampliamente cubierto por este periódico, se desarrolló de manera que inicialmente parece seguir la intención de aportar conocimientos y de destacar lo propio pero que se conviertió además en un agente de una programación proveniente de una cultura ajena, y de intereses, eso sí, profundamente transformadores de una sociedad que apunta a lo transnacional o global, mediado, claro está por la tecnología.

En resúmen, lo que se aquí es cómo un periódico vinculado esencialmente al proceso de modernidad en Colombia, con todo lo que implica la expresión de sorpresa y encantamiento con la novedad, gradualmente se transformó en un instrumento de las estrategias del más desenfrenado consumismo.

\section{El tratamiento de la noticia en los titulares}

Desde su inicio, y tal como lo anuncia en su primer editorial, Mundo al día convoca a la opinion pública de todos los sectores de la sociedad: "hacemos una llamado a todos nuestros compatriotas para que secunden nuestros propósitos y cooperen en nuestra labor y hagan de Mundo al día una auténtica tribuna nacional que traduzca y propague toda feliz iniciativa del pensamiento colombiano en sus multiples manifestaciones"14 y afirma que procurará "que nuestro diario sea variado y ameno y que por la selección de su contenido merezca la acogida amable de los hogares colombianos".

\footnotetext{
${ }^{14}$ Editorial 15 de enero, 1924, 2. 
Desde su creación, es evidente que el periódico pretende cubrir a un sector tan amplio, lo que, en términos de Guillermo Sunkel significa un contrato implícito con la matriz simbólico dramática ${ }^{15}$ en la que los sectores populares se visiblizan desde los espacios de la vida cotidiana, en el trato de temas propios de la cultura popular, tanto en el contenido escrito como gráfico. Empleando una mezcla de estilo informativo, narrativo e argumentativo, cada escrito se acomoda respectivamente a la función de relatar los hechos, legitimizándolos mediante referencias a fuentes oficiales o jerarquizadas; acercándosele al lector a través de la anécdota y la descripción para reforzar la verosimilitud; o bien, persuadiendo o conmoviendo al lector por medio de la apelación al uso de la razón (estilo que frecuentemente se utiliza para el periodismo de corte sensacionalista). ${ }^{16}$

También es evidente que existe un código tácito en ese contrato entre el periódico y el y lector, en el que se sabe que la extensión de un escrito, el tamaño de sus titulares, el uso de la primera tapa versus la contratapa, la apariencia de un titular en la parte superior de la página versus la parte inferior o el tamaño de la letra, etc. sugieren el significado que se le otorga a una noticia y su valor correspondiente. Por lo mismo, "la deixis socio-cultural, constituida por las referencias a personajes públicos, lugares de moda, libros o teorías, formas de vestir y moverse de los actores de las nitas, aporta el efecto de reconocimiento, y posibilita el verosímil porque es la realidad que 'todos conocemos',. . . acentúa la cercanía y aumenta la credibilidad.” ${ }^{17}$

Para comprobar la evolución del Mundo al día en el sentido de que, a pesar de que cada vez más se consolidan las redes de noticias internacionales, el enfoque sobre la noticia se va desdibujando, acogiéndonos al World History Timeline, ${ }^{18}$ se tomaron en cuenta los siguientes acontecimientos que marcan hitos en los años 1920 a 1938:

\footnotetext{
${ }^{15}$ Razón y pasión en la prensa popular, cultura de masas y cultura política. Santiago de Chile, ILET, 1992, 73.

${ }^{16}$ Martini, Op. cit.. 109.

${ }^{17}$ Ibid.

${ }^{18}$ www.historyexplorer.net
} 
Tabla No. 1:

\begin{tabular}{|c|c|c|}
\hline Año & Noticia & Cubrimiento \\
\hline 1920 & $\begin{array}{l}\text { Radio Corporation of America (RCA) fundada por la } \\
\text { General Electric y la American Telephone and } \\
\text { Telegraph Company (AT\&T) con el fin de } \\
\text { promocionar la radio a nivel internacional }\end{array}$ & \\
\hline 1921 & $\begin{array}{l}\text { Adolf Hitler se convierte en el Presidente del partido } \\
\text { Nazi }\end{array}$ & \\
\hline 1922 & $\begin{array}{l}\text { Benito Mussolini se convierte en Primer Ministro } \\
\text { italiano } \\
\text { Descubrimiento de la tumba de Tutankhamen }\end{array}$ & \\
\hline 1923 & Creación de la República de Turquía & \\
\hline 1924 & Muerte de Vladimir Lênin & Sí \\
\hline 1925 & Benito Mussolini se convierte en dictador en Italia & “Sí” (foto) \\
\hline 1926 & Hirohito proclamado Emperador de Japón & No \\
\hline 1927 & Primer vuelo transantlántico de Lindbergh & Sí \\
\hline 1928 & Asesinato del Presidente de México, Alvaro Obregón & No \\
\hline 1929 & $\begin{array}{l}\text { Herbert Hoover es elegido presidente de los Estados } \\
\text { Unidos } \\
\text { "Black Friday" : cae Wall Street }\end{array}$ & Sí \\
\hline 1930 & $\begin{array}{l}\text { Revolución en Brasil: Getulio Vargas se convierte en } \\
\text { Presidente }\end{array}$ & Sí \\
\hline 1931 & Al Capone juzgado y condenado & Sí \\
\hline 1932 & $\begin{array}{l}\text { Herman Göring elejido Presidente del Senado } \\
\text { alemán }\end{array}$ & No \\
\hline 1933 & $\begin{array}{l}\text { Franklin Delano Roosevelt elegido Presidente de los } \\
\text { Estados Unidos }\end{array}$ & Sí \\
\hline 1934 & Adolf Hitler se proclama "Führer" de Alemania & No \\
\hline 1935 & Italia invade a Etiopía & No \\
\hline
\end{tabular}




\begin{tabular}{|l|l|l|}
\hline $\mathbf{1 9 3 6}$ & Comienza la Guerra civil española & \\
\hline $\mathbf{1 9 3 7}$ & $\begin{array}{l}\text { Churchill nombrado Primer Ministro del Reino } \\
\text { Unido }\end{array}$ & "Sí” \\
\hline $\mathbf{1 9 3 8}$ & Las tropas alemanas ocupan a Austria (el Anschluss) & No \\
\hline
\end{tabular}

Se observa en este breve ejercicio cómo, en sus primeros años, el periódico atina en registrar noticias que a nivel internacional se asumen como importantes. mientras que, con el pasar del tiempo, no transmite noticias tan transcendentales como la proclamación que en 1934 Hitler hace de ser el Führer de su nación, ni se menciona la invasion italiana al norte del Africa (Etiopía), y aún más grave, porque el periódico frecuentemente alude a la estrecha relación con la Madre Patria, sorprende la falta de noticia alguna sobre el comienzo de la Guerra Civil en España. Por esta falta de agudeza en el seguimiento de la noticia, una mirada crítica señala que se puede inferir un enfoque alejado de la principal función de la prensa: la de transmitir las noticias. Como se verá más adelante, en este período el periódico se centra en otros aspectos, concretando el cambio también por una presentación diferente, ya que su tamaño se reduce-- no se utiliza el formato tabloide-- y se incrementa el cubrimiento publicitario, ante todo de productos foráneos.

En el seguimiento al desarrollo de los titulares, en los primeros años de circulación de Mundo al día hay varios aspectos paradójicos que vale la pena destacar. En primer lugar, en vez de referirse al nombramiento de Churchill como Primer Ministro del Reino Unido como noticia, se recurre a una estrategia menos formal pero quizás más atractiva para el lector común: se presenta una entretenida crónica sobre la figura de Churchill en su vida cotidiana, en la que no se hace mención de su importante ascenso político. Esto subraya el hecho que el valor y el significado de la noticia comparado con una crónica, o una foto, por decirlo así, es de otra categoría. Por otra parte, aunque sí se menciona a Benito Mussolini, inicialmente tan solo mediante una fotografía (ver Tabla No. 1, en el que señala el cubrimiento de la noticia con comillas), los titulares de las noticias que sobre el se transmiten en 1925 inicialmente irradian una cierta simpatía y tan solo al final del año se vislumbra una actitud crítica, como lo atestiguan los índices del periódico (ver Tabla No. 2): 
Tabla 2:

\begin{tabular}{|l|l|}
\hline Fecha & Titular \\
\hline o3/o3/25 & $\begin{array}{l}\text { Mussolini y el Rey de Italia reciben con gran entusiasmo } \\
\text { al Presidente Señor Alessandri }\end{array}$ \\
\hline $\mathbf{1 9 / 0 4 / 2 5}$ & Benito Mussolini en la jaula de los leones (foto) \\
\hline $\mathbf{2 1 / 0 6 / 2 5}$ & El periodista vale más que el político según Mussolini \\
\hline $\mathbf{o 6 / 0 9 / 2 5}$ & Mussolini visita a D'Anunzio en Cargnacco \\
\hline $\mathbf{2 2 / 1 1 / 2 5}$ & $\begin{array}{l}\text { Farinacci, el violento, es el más probable sucesor de Mussolini en la } \\
\text { jefatura del gobierno fascista }\end{array}$ \\
\hline $\mathbf{2 3 / 1 2 / 2 5}$ & Sueños imperiales de Mussolini \\
\hline
\end{tabular}

Haciendo un ejercicio similar con las noticias nacionales (Tabla No. 3), además de acudir a la Timeline para Colombia, se tomó como referencia el estudio que de los años veinte y sobre la mentalidad del colombiano hiciera Carlos Uribe Celis (1985 y 1991 respectivamente). ${ }^{19}$

Tabla No. 3

\begin{tabular}{|c|c|c|}
\hline Año & Titular & Cubrimiento \\
\hline 1924 & $\begin{array}{l}\text { Aura o las violetas de Vargas Vila se lleva a la } \\
\text { pantalla }\end{array}$ & Sí \\
\hline 1925 & $\begin{array}{l}\text { Ingresan los dineros de la indemnización por } \\
\text { Panamá }\end{array}$ & Sí \\
\hline 1926 & Creación del Ministerio de Justicia & Sí \\
\hline 1927 & $\begin{array}{l}\text { La United Press Assocacion abre oficina en } \\
\text { Bogotá }\end{array}$ & Sí \\
\hline 1928 & Huelga bananera, United Fruit Company (foto) & Sí \\
\hline 1929 & $\begin{array}{l}\text { Rómulo Rozo es nombrado decorador del pabellón de } \\
\text { Colombia en la Exposición Iberoamericana de Sevilla }\end{array}$ & Sí \\
\hline 1930 & $\begin{array}{l}\text { Enrique Olaya Herrera se convierte en el primer } \\
\text { presidente liberal después de la hegemonía }\end{array}$ & Sí \\
\hline
\end{tabular}

${ }^{19}$ Los años veinte en Colombia. Ideología y cultura. Bogotá, Ediciones Alborada, 1991 y La mentalidad del colombiano. Cultura y sociedad en el siglo veinte. Bogotá, Ediciones Alborada, 1992. 


\begin{tabular}{|c|c|c|}
\hline & $\begin{array}{l}\text { conservadora de } 50 \text { años. } \\
\text { Las mujeres acceden al Bachillerato }\end{array}$ & \\
\hline 1931 & Muere el caricaturista Ricardo Rendón & Sí \\
\hline 1932 & $\begin{array}{l}\text { Comienza la Guerra con el Perú } \\
\text { Llega el cine mexicano y argentino a Bogotá }\end{array}$ & Sí \\
\hline 1933 & $\begin{array}{l}\text { Se decreta la fundación de la Academia Nacional de } \\
\text { Ciencias } \\
\text { Aparece en Bogotá la emisora La Voz de Victor }\end{array}$ & $\begin{array}{l}\text { Sí } \\
\text { No }\end{array}$ \\
\hline 1934 & Se firma el Protocolo de Rio de Janeiro con el Perú & Sí \\
\hline 1935 & $\begin{array}{l}\text { Muere Carlos Gardel en un accidente aéreo en } \\
\text { Medellín } \\
\text { Se iniciala programación radial en vivo }\end{array}$ & \begin{tabular}{|l|} 
Sí \\
No
\end{tabular} \\
\hline 1936 & $\begin{array}{l}\text { Reforma Constitucional de Alfonso López Pumarejo } \\
\text { Fundación de la Facultad de Arquitectura de la } \\
\text { Universidad Nacional }\end{array}$ & $\begin{array}{l}\text { Sí } \\
\text { No }\end{array}$ \\
\hline 1937 & Surge el cine parlante & No \\
\hline 1938 & $\begin{array}{l}\text { Hombres sin presente de Osorio Lizarazo } \\
\text { Salen las primeras radio novelas }\end{array}$ & $\begin{array}{l}\text { No } \\
\text { No }\end{array}$ \\
\hline
\end{tabular}

Habiendo aplicado el mismo ejercicio a las noticias nacionales, se observa el mismo fenómeno, en el sentido de que durante los primeros años hay una mayor sensibilidad a las noticias importantes, mientras que, a partir de los años treinta disminuye considerablemente la capacidad o el interés de abordar la noticia de manera integral. Nuevamente surge la paradoja sobre la mirada desde la que se hacen reportajes sobre Panamá en Mundo al día, y se percibe un sentido de identificación nacionalista con Panamá que parece totalmente descontextualizada de los hechos nefastos que precipitaron la separación de Panamá en $1903 .{ }^{20} \mathrm{~A}$ continuación se transcriben los titulares del año 1925 (el año en que se reciben los primeros dineros de indemnización) relacionados con Panamá:

\footnotetext{
${ }^{20}$ Palacios y Safford, op. cit., 468. 
Tabla No. 4:

\begin{tabular}{|l|l|}
\hline Fecha & Titular \\
\hline $\mathbf{1 3} / \mathbf{0 1} / \mathbf{2 5}$ & Antonio Velez Lora en Panamá: entrevista \\
\hline $\mathbf{1 0 / 0 4 / 2 5}$ & Debilidad de las defensas del canal de Panamá \\
\hline $\mathbf{2 1 / 0 4 / 2 5}$ & Ha muerto en Panamá el general A Gardeazabal \\
\hline $\mathbf{0 6 / 0 5 / 2 5}$ & Rafael Plata (boxeador) luchará en Panamá \\
\hline $\mathbf{2 6 / 0 6 / 2 5}$ & Rafael Plata (boxeador) luchara en Panamá \\
\hline $\mathbf{1 4 / 1 0 / 2 5}$ & Panamá ocupada militarmente \\
\hline $\mathbf{1 5 / 1 0 / 2 5}$ & Grandes desordenes en Panamá \\
\hline $\mathbf{1 8 / 1 0 / 2 5}$ & En Panamá hoy ya reina una completa tranquilidad \\
\hline
\end{tabular}

La sensación que se tiene es que Colombia aún no asimila el hecho que Panamá ya no le pertenece, y que sus problemas internos no son ajenos al país. Un año más tarde, cuando se desembolsan los últimos dineros a Colombia, ya se percibe un espíritu mucho más crítico, hasta el punto de que aparece un titular diciendo "Panamá, una colonia americana” (Enero 22, 1926).

\section{El tratamiento de la imagen}

Según Martini, el material ilustrativo (fotografías, gráficos, dibujos) se constituye cada vez más en el punto de anclaje para la atención del lector. Las fotografías adquieren un valor significante en la construcción de lo verosímil: lo que no alcanzan a describir las palabras lo muestran las imágenes, y agregan la fuerza del testimonio, el "haber estado allí" 21 Por lo mismo, en vista de que un importante acervo de la noticia se transmite en Mundo al día mediante el uso de fotografías, carátulas, caricaturas y gráficos de diversa índole, en un análisis concienzudo del periódico no puede faltar la imagen. Esto, sumado al interés de las directivas de acceder a un público cada vez más amplio, y no necesariamente el más educado,

\footnotetext{
${ }^{21}$ Martíni, Op. cit., 115. 
aunque fuera con la finalidad de formar sus gustos y sus valores mediante recursos visuales novedosos.

Es necesario precisar que, por su riqueza gráfica y publicitaria, fue imposible hacer un índice completo de este aspecto del periódico, aunque se intentó hacer una selección representativa, ante todo de los años 1924 a 1929 o sea, de la primera época del periódico, ya que los años veinte fueron los años más importantes en materia de consolidación de la población urbana y de la modernización del estado y de las comunicaciones. $^{22}$ Se justifica esta medida además porque, por otra parte, desde 1927, cuando ya no se habían concluido los desembolsos de la indemnización de Panamá, Colombia además presenció un notable declive económico que continuó a partir del "crack" de Wall Street de 1929, y se agudizó con los sucesos que llevaron a la Guerra con el Perú en 1932. Uno de los efectos más notables fue la transformación de Mundo al día en, ya no en diario gráfico, sino en semanario, reduciendo su formato tabloide al de magazin.

Para efectos de organización, las imágenes se agruparon en tres grandes categorías: aquellas que constituyen lo que llamaremos un espejo de la Colombia que se quiere proyectar. En esta categoría están el sinnúmero de fotografías que muestran el enorme desarrollo en materia de transportes y comunicación. También figuran las fotografías que muestran el desarrollo de las ciudades, de los puertos y de las industrias, con frecuencia tomadas desde el aire (bien acordes con el advenimiento de la aviación colombiana). En esta categoría también se observa la sentida necesidad de difundir y proyectar lo propio: las carátulas en forma de cartel gráfico a color frecuentemente presentan o bien escenas tradicionales o bien imágenes que acentúan el advenimiento de la modernidad.

Así como en cierto momento las tarjetas de presentación con foto eran un mecanismo de hacerse conocer en nuestro medio, el periódico se perfila como una cartilla de presentación a esa gran sociedad dentro y fuera de las fronteras nacionales y para ello, protagonizan las fotos de periodistas colombianos visitando al dueño del New York Times, de empresarios como el propietario del periódico, Arturo Manrique, posando junto al presidente Coolidge en Washington, por dar tan solo

\footnotetext{
${ }^{22}$ Uricochea, Fernando. Modernización y desarrollo en Colombia: 1951-1964. Bogotá, Editorial Iqueima, 1968, 54. 
algunos ejemplos. El rol significativo que se le adjudica a este medio de comunicación entonces se refleja por el hecho que abundan los artículos, las editoriales y la considerable propaganda sobre el éxito en términos de tiraje y difusión del mismo, además de la relación directa entre los resultados de las ventas de productos que se publicitan a precios ventajosos. En efecto, abruma el énfasis sobre la proyección del periódico y el número de lectores que tiene.

Asímismo se señala constantemente la importancia del periodismo y se dedican páginas extensas a indagar sobre los vínculos con otros periódicos y agencias a nivel internacional. Repetidamente se observan cuantiosos avisos y escritos sobre la función de este periódico como forjador de cultura y de nación, no sin señalar el interés que tiene para sus lectoras femeninas y para los niños. Por último, es interesante observar que los propietarios y las directivas del periódico no figuran entre las élites políticas del país y hay poca información concreta y al parecer, menos interés en asumir un protagonismo como tal, quizás con la excepción de Adolfo Samper, pero más por el hecho que predomina como autor, como caricaturista, como grabador, como diseñador de las carátulas, y como autor de la primera tira cómica del país, "Mojicón y Gelatina”. Ocasionalmente figuran otros ilustradores por esta época ante todo en semanarios o revistas culturales en nuestro medio y en nuestro continente.

Un tema favorito para las carátulas es la fotografía de las actrices (en la mayoría de los casos, extranjeras) de las primeras películas colombianas. También protagonizan el uso de la caricatura y de la tira cómica, que por vez primera aparece en Colombia en Mundo al día bajo la figura del "Mojicón," un personaje sui generis, cuya principal función es la de representar e ironizar la cultura "cachaca", los modales, el lenguaje y la vida cotidiana de la población urbana en Bogotá. Finalmente, como un mecanismo para afirmar la sentida necesidad de constuír el estado nación, se acude a la publicación semanal de una partitura de música colombiana (pasillos, bambucos, torbellinos) para piano o para piano voz. ${ }^{23}$ Tal y como lo dice el compositor Blas Emilio Atehortúa:

\footnotetext{
${ }^{23}$ Friedmann, Susana. "Avance de la investigación del diario de la tarde, Mundo al día, Revista Ensayos del Instituto de Investigaciones Estéticas No 5, 1998-99, 265-96.
} 
Pareciera que, así como lo observara hacia el final del siglo diecinueve Menéndez y Pelayo, la "Atenas suramericana" sintiera la necesidad de proyectar ese ingrediente propio y diferente. . . . Lo que sorprende es que los editores del periódico hayan optado por plasmar una identidad nacional a través de una grafía musical, una grafía a la que, sin lugar a dudas, no todos los lectores podían acceder. ¿Será que, por su presentación impecable a la vez que indescifrable, la notación musical evocaría por una parte, un gran sentido de cultura, un símbolo de esa ciudad letrada, y por otro, quizás serviría para atenuar el abismo social entre una sociedad de élites frente al fenómeno de lo popular, y específicamente, de la música popular? ${ }^{24}$

Sea cual fuera la razón, en síntesis, tomando el conjunto de estas imágenes diversas, se respira un aire de sorpresa y de entusiasmo, de una plena confianza en la modernización del país y en el advenimiento de tiempos mejores.

Irónicamente, el personaje "Mojicón", aunque caricaturiza a la figura del cachaco bogotano, es copia del personaje "Smithy," tomado del diario Daily News como modelo. Adolfo Samper, el artista, nunca firmó esta tira, por cuanto consideraba que no era creación suya y por lo tanto no quería que se le atribuyera a él.

Otra categoría corresponde a lo que llamaremos los reflejos. Reflejos de una sociedad cuyo progreso en gran parte se mide por una modernización introducida por países más desarrollados y más poderosos. En esta categoría están las carátulas de actrices norteamericanas, de presidentes norteamericanos, y de los primeros aviadores internacionales además de un nutrido contenido de fotografías sobre personalidades de todo el mundo, muchas veces acompañando al propietario del periódico en uno de sus viajes al exterior. En muchos casos, las fotos de las personalidades de proyección internacional (ante todo del mundo del entretenimiento), tienen la particularidad de aparecer con efusivas dedicatorias al Mundo al día. Algo parecido sucede con las partituras que se incluyen los sábados, muchas de las cuales son dedicadas a personalidades mencionadas en la edición del mismo día o destacadas en el medio periodístico, artístico y de vez en cuando político.

Uno de los aspectos más insólitos de esta categoría de imágenes es que suelen aparecer firmadas por personajes célebres, de manera que personalizan la

\footnotetext{
${ }^{24}$ Introducción a las notas al disco Revivamos nuestra música, 1. 
relación con el periódico. Así, la Mistinguette escribe un mensaje efusivo a los lectores de Mundo al día, y Thomas Alva Edison se dirije "afectuosamente" a los editores del periódico. Esto crea una sensación de cercanía al primer mundo y legitimiza el papel transcendental como puente que pretende cubrir el Mundo al día.

En la misma categoría está, por supuesto, la publicidad, que cada día cubre mayor espacio en el periódico. En los avisos publicitarios se orienta con lujo de detalles sobre los últimos artículos de moda, sobre inventos que aumentan la precisión y la eficiencia de las empresas (desde sus sistemas de archivo hasta su contabilidad), sobre los últimos tratamientos para las dolencias comunes, sobre los últimos modelos de calzado, de sombreros, y de medias de seda. Así se percibe ante todo el enorme influjo de mercancías europeas y norteamericanas: maquinaria industrial y electrodomésticos, alimentos y brebajes típicos de una sociedad moderna: la avena Quaker Oats, el té Lipton, los electrodomésticos de la General Electric, Westinghouse y de empresas alemanas; siguen los medicamentos (la gran mayoría americanos, como el jarabe Dr. Chase y el Aceite Johnson, por nombrar tan solo a dos). Frecuentemente, los avisos publicitarios aparecen con leyendas extensas que, en vez de repetirse al día siguiente, cambian de pauta cada día para cautivar y conmocionar así a su público, formando verdaderas series que apuntan el producto con las más audaces estrategias de mercadeo. ${ }^{25}$ Según Mariluz Vallejo, Mundo al día fue el primer periódico que, en 1928 contrató al primer "cronista-publicista", quien, tras haber ejercido en esta capacidad en varios periódicos suramericanos, se dedicó a escribir cónicas sobre las grandes empresas y así promoverlas, en este caso, con una extensa crónica sobre la casa de discos Víctor, subsidiaria de La Voz de Victor, la más importante empresa discográfica en los Estados Unidos en los años veinte. ${ }^{26}$

Un importante capítulo de la historia de la radio en Colombia anterior a $1929^{27}$ queda consignado en las páginas de Mundo al día desde 1925, cuando se

\footnotetext{
${ }^{25}$ Baquero, Angela. La publicidad en el diario Mundo al día. Tésis de Diseño Gráfico. Universidad Nacional de Colombia, 2004.

${ }^{26}$ Vallejo, Mariluz. A plomo herido. Una crónica del periodismo en Colombia (1880-1980), Bogotá, Planeta Editorial, 2006, 372.

${ }^{27}$ En septiembre 5 de 1929 inicia actividades la HJN, la primera emisora oficial colombiana que en 1931 fue puesta al servicio de la Biblioteca Nacional y en 1940 se convirtió en la Radiodifusora Nacional de Colombia (Vizcaíno Gutiérrez, Milciades. La HJN: precursora de la radio colombiana y soporte en la construcción del Estado-Nación. Bogotá, Universidad del Rosario, 2002, 34).
} 
anuncia la primera transmisión radial del país. Es otra instancia en la que el aporte de Mundo al día ni siquiera es registrado por nuestros historiadores y periodistas, y sin embargo, el papel del propietario del periódico fue significativo, tanto por sus nexos comerciales como por su constante interés en ofrecer los últimos adelantos en materia de de radiocomunicación y en la posibilidad de propiciar aún otro medio adicional al del periódico para abrir las fronteras accidentadas del país a los nuevos medios de comunicación.

Además del cubrimiento de las novedades sobre el proyecto de transmisión radial al país (proyecto bastante complicado, acentuado por la topografía accidentada del país), desde 1929, el periódico ofreció una Sección intitulada Radiotelefonía, que transcribía para un público de unos 500 receptores ${ }^{28}$ la programación radial, entre otras, de la WGY de Schenectady (vinculada a la General Electric Company) ${ }^{29}$ y posteriormente, de la Emisora HJN y de la HKF, "Voz de Bogotá" (primerca emisora de carácter comercial, cuya programación era ofrecida por Almacenes Victor), en su primera etapa tan solo musical pero a partir de 1935, una nueva manera de hacer periodismo vivo. El interés de esta sección de radiotelefonía reside en el hecho que, en primer lugar, se puede reconstruír el repertorio musical que se podía escuchar desde el país (clásico como popular), pero más importante aún, quedan registradas las grabaciones de músicos colombianos y latinoamericanos que viajaron a Nueva York en esta época, varios de los cuales interpretaron obras de la colección de partituras ofrecidas por Mundo al día y además eran colaboradores estrechos del periódico, como es el caso de Martín Alberto Rueda, por nombrar a uno de las grandes personalidades que trabajó en el campo de la dirección de orquestas para la radio en Colombia, en Méjico y en Costa Rica.

Finalmente, está la categoría que corresponde a los imaginarios: los miedos y los prejuicios pero tambien las pretensiones o las valoraciones de una sociedad que se cree estar perfectamente "al día” en materia de tecnología, comunicación y cultura. No podrían faltar los crímenes, los miedos y el terror, ingredientes esenciales para garantizar un público lector asiduo y constante. En el Mundo al día se complace con creces al lector interesado en conocer cada detalle de los últimos juicios y los últimos

\footnotetext{
${ }^{28}$ Arias, Eduardo. "Comienza a emitir la HJN: Colombia al aire” Revista Semana \# 1163 (mayo a junio), 2004, 155 .

${ }^{29}$ www.wikipedia.com
} 
escándalos, preferiblemente con grotescas imagenes gráficas que permitan reconocerse en medio de todo ese imaginario urbano. A este tipo de lector seguramente también están dirigidos los frecuentes avisos de las últimas armas y equipos de seguridad y las advertencias al público para prepararse ante las amenazas que nos asedian a diario.

Pero aquí también es en donde aparecen las fotografías de miembros de la sociedad en carátulas impactantes que muestran a la sociedad colombiana en elaborados marcos como los que suelen exhibir monarcas y soberanos (aspecto bastante común en los periódicos de la época), dándole un carácter intimista a la noticia local como lo proporciona un album de familia. De esta forma, en Mundo al día de los años veinte y treinta se perfilan de esta manera personalidades de cierta proyección local pero con una gran aspiración de reconocimiento internacional que se presentan en carátulas tipo espejo, cuya función, como bien es sabido, es reconocerse, como ya se ha señalado ante todo con las impactantes carátulas del periódico, muchas de ellas a color y con diseños

En sentido contrario y con el fin de reenforzar el espíritu comunitario y democrático, aparecen las carátulas que exaltan el espíritu colectivo: los carnavales de estudiantes, la representación de figuras del pasado heróico, o bien de la mujer liberada con sus gestos atrevidos como el de una mujer fumando. Y también aparece la representación bastante sórdida de lo que son las nuevas tecnologías, frecuentemente desde una mirada desconfiada y hasta despectiva como sucede con la carátula del 18 de septiembre de 1930, en que se presenta el micrófono más bien como un agente de la prostitución y de lo ordinario que como herramienta de perfeccionamiento en la difusión del sonido.

Igualmente, la manera como se trata el tema de la negritud muestra un desprecio enorme y una actitud racista sin tapuos. Así, sorprende la manera cómo se trata el advenimiento del jazz. La carátula del 12 de mayo de 1928 presenta un conjunto de jazz con un claro sesgo racista, empleando la figura del simio--negro, claro está-- en vez de seres humanos tocando los instrumentos propios de esta nueva cultura musical. En el mismo tono desconconcertante la carátula de marzo 28 de 1925 muestra uno niños con su sirvienta, golpeando las tapas de unas ollas y un perro aullando, nuevamente para representar el jazz! Sin duda alguna, la lectura de 
estas imágenes envía un mensaje tanto racista como clasista, mostrando de esta manera que, a pesar de considerarse agentes del progreso y de modernidad, el equipo de Mundo al día pertenece a una sociedad llena de perjuicios y con poco aprecio por culturas que están en camino a legitimarse, como es el caso del jazz (que por cierto fue acogido con entusiasmo en Europa y constituyó un eslabón importante en la consolidación de la cultura (no de la economía) norteamericana.

Otro ejemplo impactante de esta mirada nefasta aparece en un aviso de publicidad, en el que se ve una enorme cama con tendido blanco y una diminuta criatura, cuya cara revela su raza. La niña le suplica a la mamá que consiga la crema blanqueadora Mollis. Es un aviso que caricaturiza el deseo de borrar todas las diferencias étnicas y raciales que constituyen el perfil del ciudadano colombiano, producto de un fuerte mestizaje que incluye altos porcentajes, entre otros, de sangre indígena, española y negra, pero que en los años veinte y treinta se ocultaba frente a una fachada de unicidad y homogeneización extraordinaria. ${ }^{30}$ Tanto la imagen diminuta de la niña que quiere blanquear su piel y que a duras penas se puede ver, como el texto, muestran claramente los perjuicios sociales y culturales que prevalecen aún hoy en muchos sectores de la población colombiana.

En esta categoría de imágenes se registra también la sensibilidad a ciertos fantasmas de la modernidad, como es el caso del imaginario urbano, como sucede con una figura satánica en perfil rojo que aparece al fondo de la página de clasificados y la que reaparece como "el fantasma del suburbio," ese mismo personaje que aparece surrepticiosamente en la página de clasificados con el mensaje de: "siempre consigo todo lo que deseo en la sección de avisos de Mundo al día” ${ }^{\text {1 }}$

El valor que se le atribuye a todas estas imágenes muestra que Mundo al día no escatima todos los recursos que tiene a su disposición para atraer a un público amplio que incluye no solo a la gente letrada, sino también a las mujeres (no necesariamente la mujer educada), a los niños (con su tira cómica) y a una enorme población analfabeta que tan solo puede acceder a la noticia mediante la imagen. Tanto así, que se puede comprobar que, con el pasar del tiempo, tanto las fotografías, las carátulas y aún los avisos publicitarios contienen información de mayor

\footnotetext{
${ }^{30}$ Aviso para Crema Mollis, Mundo al día, 4 de agosto, 1927, 19.

${ }^{31} 19$ de junio, 1928, 101.
} 
ingerencia en la vida de los colombianos que los artículos extensos así como las secciones anteriormente consideradas como las prioritarias, lo que puede ocasionar una lectura que subvierte el orden de lo que se legitimiza) $)^{32}$. Un ejemplo contundente de ello es el hecho que la huelga bananera de 1928 se anuncia, no en los titulares o mediante un escrito, sino sencillamente con que unas fotos que impactan. En otras palabras, un periodismo centrado obsesivamente en lo escrito-- es más-- un análisis cultural con un sesgo estrictamente letrado, indudablemente incurre en una lectura parcializada y poco sensible al valor de la comunicación visual y sus alcances.

Y también, el ejemplo de la evolución de Mundo al día demuestra que la función del periódico es algo que sufre procesos de transformación que no necesariamente son contradictorios a los intereses cambiantes de una sociedad. Producto de una dirección y de un equipo que inicialmente era intelectual y en ocasiones político, con el pasar de los años, se convirtió en gran medida en un empeño indiscutiblemente empresiarial, constituyéndose cada vez más en un agente, no de noticia, sino de novedad, de noticiabilidad, y en esto, claro está, la mercancía que se vende, sea el progreso (el cine, la radio), la comunicación (el periodismo, la imprenta y la industria del papel) y el transporte (la industria automotriz y la aviación), mostrando así el engranaje que existe entre comunicación y cultura, en este caso, íntimamente ligado a los intereses comerciales de su propietario como agente de la modernidad y del progreso.

\footnotetext{
${ }^{32}$ Tanto así que Mariluz Vallejo, en su crónica sobre la prensa colombiana, ejemplifica la superficialidad con que trata la noticia Mundo al día, al informar que por ejemplo "apoyó con entusiasmo la huelga de los telefonistas de Bogotá por los malos salarios que les pagaba la compañía inglesa, pero pasó por alto la masacre de las bananeras," op. cit, 66, sin percatarse de que en cambio aparecen en primera página unas fotos que impactan por la devastación que muestran (8 de enero de 1929).
} 